\title{
Do we miss half of the injuries sustained during rape because we cannot see them? An overview of the use of toluidine blue tissue stain in the medical assessment of rape cases
}

\author{
JM Kotzéa* iD and H Brits ${ }^{b}$ iD \\ ${ }^{a}$ Department of Forensic Medicine and Department of Family Medicine, University of the Free State, Bloemfontein, South Africa \\ ${ }^{b}$ Department of Family Medicine, University of the Free State, Bloemfontein, South Africa \\ *Corresponding author, email: MaraisJM@ufs.ac.za
}

The prosecution of rape cases is difficult due to the absence of eyewitnesses. McCauley found that the detection of vaginal lacerations increased from one in 24 to 14 in 24 in reported adult rape cases when toluidine blue was used. Proof of injuries consistent with sexual penetration adds significantly to the evidentiary value of the medico-legal testimony. Although rape is not a clinical diagnosis and there are no diagnostic criteria to confirm rape, the possibility of genital injury during rape far exceeds the possibility of injury with consensual intercourse. If a complete examination, including the use of toluidine blue, is not used a rapist may walk away to rape again, while the victims remain with the stigma that they may have made a false allegation.

Toluidine blue is a basic thiazine metachromatic dye. It has a high affinity for acidic tissue components, thereby staining tissues rich in DNA and RNA. The epithelium of the external genitalia does not have nucleated cells and prevents contact of stain with nuclei. Where the epithelium is damaged and the underlying nucleated cells are exposed, the nuclei stain blue. Injuries sustained during genital penetration show a distinctive distribution.

Toluidine blue stain is easy and safe to use, available, inexpensive and does not interfere with other medico-legal evidence, therefore it is recommended to be used in the examination of all cases of alleged rape.

Keywords: examination, rape, sexual assault, tissue stain in vivo, toluidine blue

\section{Introduction}

In adult and adolescent rape cases, conviction is more likely if there are visible injuries. ${ }^{1-3}$ It may be that medical examinations are routinely done in a way that prevents the detection of a large percentage of anogenital injuries. Is it possible to improve the visibility of post-coital injuries? Research, clinical experience of experts and personal experience suggest that this is possible. ${ }^{4-8}$

The health practitioner has the responsibility to search for genital and anal injury to corroborate that penetration is likely to have occurred. Visibility of the nature of injuries, number of injuries and number of anatomical sites injured can be vastly improved utilising a nuclear tissue stain such as toluidine blue, to highlight epithelial damage. ${ }^{9}$ Injuries can either be confirmed after visual examination with the naked eye, or detected when not visible without the staining technique by the use of a scientific process to increase visibility.

Rape is sexual penetration without consent. The presence of injuries may support the history of genital and/or anal penetration and also suggests the likely absence of cooperation. Due to the fact that the defence in rape cases, more often than not, claim that the deed was done with consent of the victim, improvement of visibility of injuries may support the allegation that consent was absent.

\section{The nature of anogenital injuries after penetration}

The most likely structures to be injured during genital penetration are the posterior fourchette, the fossa navicularis, the hymen and the labia minora. ${ }^{9}$ The genital and anal injuries generally found during the clinical examination are subtle. Genital injuries are usually shallow and do not show blood on the surface. Peri-anal injuries, as a result of penetration from the outside, are generally in the form of multiple radial tears of the perianal area inside and outside the midline and extending into the anus.
It may be difficult to distinguish normal irregular tissue structures from injuries. The colour of the normal tissue of the fossa navicularis may be similar to that of injured tissue. Alternatively, injuries may be over-diagnosed for the same reason. ${ }^{10}$ Slaughter found that injuries due to cooperative, consensual genital penetration are generally limited to a small injury of one genital anatomical site. If more than one genital site is injured, the likelihood that the penetration took place with consent and cooperation decreases. ${ }^{9}$

\section{Toluidine blue}

Toluidine blue is an effective aid in the examination of acute rape and child sexual abuse cases. Although it is recommended as an aid for less experienced clinicians, it is of immense value for experts as well. ${ }^{5}$

It is safe to use in vivo in humans. Although a stinging sensation may occur, it does not have any long-term adverse effects. Regarding the medico-legal management, it does not interfere with biological evidence.

- Synonyms: basic blue 17, blutene chloride, methylene blue T50, Textra, tolonium chloride, methylanaline, aminotoluene. ${ }^{11,12}$

- Empirical formula: C15H16CIN3S<smiles>Cc1cc2nc3ccc(=[N+](C)C)cc-3sc2cc1N</smiles>

- Molecular weight: 305.83.

- Molecular structure: shown below 
Toluidine blue is a basic thiazine metachromatic dye. It has a high affinity for acidic tissue components, thereby staining tissues rich in DNA and RNA. ${ }^{12}$ The epithelium of the external genitalia does not have nucleated cells and prevents contact of stain with nuclei. Where the epithelium is damaged and the underlying nucleated cells are exposed, the nuclei stain blue. Injuries sustained during genital penetration show a distinctive distribution.

\section{Mechanism of application of toluidine blue}

Tissue should be visually examined with the naked eye before the application of toluidine blue. The area is then gently blotted with a swab to remove barriers between the dye and the tissue. A $1 \%$ aqueous solution of toluidine blue is applied with an earbud to the area behind the 3-9 o'clock line of the posterior fourchette or the peri-anal area. After approximately one minute, the stain is removed with a water-based lubricating gel (e.g. KY Jelly ${ }^{\oplus}$ ) or a $1 \%$ acetic acid solution on a cotton wool swab. In the case of children, the stain should be removed gently with an earbud soaked in the lubricating gel to avoid contact with the hymen. The stain will be removed from intact epithelium and be visible as a blue stain of the exposed nucleated cells.

\section{Increased detection of injuries with toluidine blue}

Literature on the utilisation of toluidine blue in the assessment of rape cases is scant. McCauley found that the detection of vaginal lacerations increased from one in 24 to 14 in 24 in reported adult rape cases when toluidine blue was used. ${ }^{6}$ Regarding adolescents, the application of toluidine blue in comparison with the naked eye increased the number of visible injuries from $4 \%$ to $28 \%$. In paediatric sexually abused patients, the visibility of posterior fourchette injuries with the naked eye was $16.5 \%$ and increased to $33 \%$ with the use of toluidine blue. ${ }^{5}$

A study by Lauber and Souma detected injuries in one out of 22 patients after consensual intercourse. ${ }^{4}$ When patients were examined with the aid of toluidine blue within $48 \mathrm{~h}$ after alleged rape, $70 \%$ of nulliparous females and $40 \%$ of the total number of patients demonstrated toluidine blue-positive laceration. ${ }^{4}$

In Slaughter and her co-workers' study, genital injuries were found in $11 \%$ of females after consensual intercourse and $89 \%$ after rape. ${ }^{9}$ Injury associated with consensual intercourse is usually limited to one genital site; injury of more than one genital site, when found, was associated with non-consensual intercourse. The use of toluidine blue may improve the visibility of injury of additional sites. The authors of this article draw attention to the fact that the detection of injuries with the aid of toluidine blue is independent of the examiner's skill.9

Although rape is not a clinical diagnosis and there are no diagnostic criteria to confirm rape, the possibility of genital injury during rape far exceeds the possibility of injury with consensual intercourse. ${ }^{9}$

Toluidine blue is also effective in post-mortem examinations. ${ }^{13}$

\section{Effects on DNA detection}

In a study by Hochmeister et al., the researchers investigated the effect of toluidine blue on the detectability of DNA. Post-coital vaginal swabs were taken $6 \mathrm{~h}$ after sexual intercourse. A $1 \%$ toluidine blue aqueous solution was used to highlight injury and subsequently destaining agents were applied (1-10\% acetic acid, and various surgical and vaginal lubricants). The result of the study reported no adverse effects on DNA detection and identification with the use of toluidine blue. ${ }^{14}$

\section{Tattooing}

Toluidine blue stain does not cause tattoos, but stains clothing.

The colposcopic images in Figure 1 are from a two-year-old boy who was abducted. He was returned $9 \mathrm{~h}$ later. The examination was done in the right lateral position with gluteal separation (Figure 1a). On examination, the finding was inconclusive with the naked eye; the presence of normal perianal skin folds impaired visibility of lacerations. Toluidine blue was applied to the perianal area (Figure 1b). The image on the right (Figure 1c) was taken after removal of the stain. A perianal tear in the 1 o'clock location was confirmed. The feature in the area from 9 to 12 o'clock is due to the gel substance that was used to remove the tissue stain.

\section{False-positive results}

Toluidine blue stains all exposed nucleated cells and yields positive results in vulvitis, herpes and other ulceration, selfinflicted injury (e.g. scratching), dermatological conditions and more. In cases where the cause of the disruption of the epithelium is not clear, the history should be used to suggest a differential diagnosis which should be investigated as indicated. Falsepositive findings may also be caused iatrogenically. The insertion of a speculum or stretching of tissue should be delayed until the toluidine blue is applied and removed.

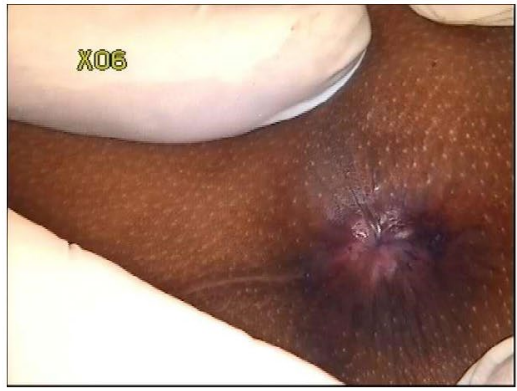

(a)

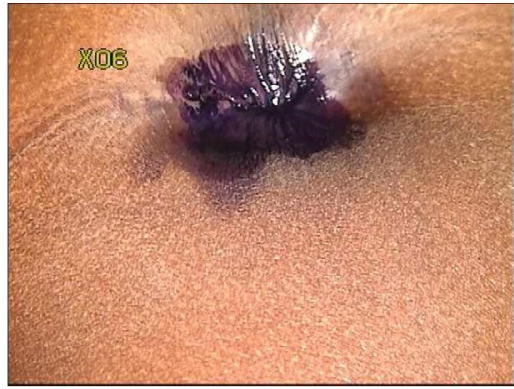

(b)

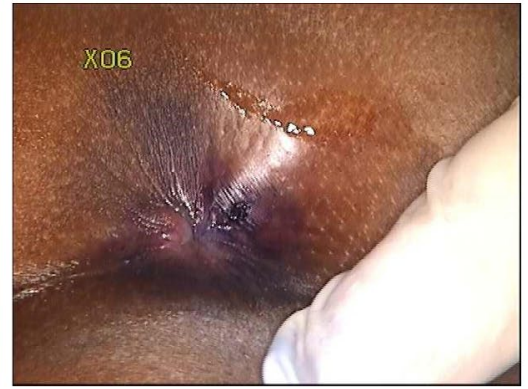

(c)

Figure 1. Three photos of a boy, (a) before toluidine blue application, (b) after toluidine blue application and (c) with the tear visible after removal of toluidine blue.

Notes: consent from the parents to use the photographs—unidentifiable for training, peer review, research and publication purposes—has been obtained. 


\section{False-negative results}

Injuries may be missed if there is a barrier between the tissue and the stain. Barriers include lubricating gel and oozing. Healing also interfere with the staining of injuries. Experience shows that injuries may still be highlighted with the use of toluidine blue more than $48 \mathrm{~h}$ after the alleged incident, which was used as a cut-off point by McCauley et al. ${ }^{5}$

Listed below are pointers for distinguishing between positive findings due to other causes and findings due to penetration: ${ }^{9}$

- The distribution and nature of the damaged area differs between the different causes of epithelial damage.

- In herpetic and other ulcerative conditions, the stain will show up in the typical minor breaks in the muco-cutaneous epithelium.

- Vulvitis presents as a patchy uptake of dye and is unlikely to be symmetrical.

- Self-inflicted injury due to scratching may be present in the presence of a history of itching. It will unlikely present as single visible abrasions and will have an irregular appearance. Dermatological conditions or infection causing itching should be excluded.

- The distribution of tears is linear and generally occurs at the fossa navicularis and the posterior fourchette in the area behind the 3-9 o'clock location of the genitalia.

- Abrasion due to genital penetration appears as a diffuse blue area in a symmetrical distribution in the fossa navicularis.

- Generally, genital injuries due to genital penetration of the female are located between 5 o'clock and 7 o'clock on the fossa navicularis and the posterior fourchette.

\section{Alternative nuclear stains}

Possible tissue-staining agents mentioned in an article by Sommers are gentian violet, Lugol's solution, toluidine blue, fluorescein, or a combination of these staining techniques. ${ }^{15}$ Lugol's solution is used to detect cervix carcinoma and premalignant lesions of the genital tract, and fluorescein is used in the detection of epithelium damage to the eye. The authors have no experience with the other agents.

\section{Price}

Toluidine blue stain is available in powder form. The recommended solution strength is $1 \%$ in water. The current cost for the Department of Health in the Free State is R2 510 for 25 grams. The solution is then used for multiple applications, which is the practice in the Free State Thuthuzela Care Centres. An individual application is the amount absorbed by an earbud. The current practice of using one container of toluidine blue by repeatedly inserting clean swabs to examine multiple patients may be a concern regarding the possible transfer of infections.

Single applications are available under the trade name Forensic Blue Swabs. Each consists of a soft foam-tipped swab with a reservoir that contains $1 \%$ toluidine blue dye aqueous solution. By squeezing the reservoir, the solution is soaked into the swab for application. ${ }^{16}$

\section{Discussion}

The presence of anogenital injuries in rape cases is of major importance in court hearings. The general perception is that rape should result in injuries. Since prosecutors only prosecute rape cases when they expect a conviction, they may be reluctant to prosecute cases where there are no injuries. With the use of toluidine blue, injuries are demonstrated in more rape victims.

The defence is generally that the sexual act was consensual and the regular question is: 'Can you rule out consensual intercourse on grounds of the medical examination?' One has to concede that the scenario is possible regardless of the clinical picture. What the prosecutor needs in order to reason with authority is the additional remark: 'Yes, it is possible, but in this case it is unlikely since I found injuries of more anatomical sites than I would expect from consensual and cooperative intercourse.'

The injuries may be present, but may not be visible due to lack of relatively inexpensive attainable resources. A rapist may walk away to rape again, while the victims remain with the stigma that she/he may have made a false allegation.

Acknowledgements - Ms T. Mulder, medical editor, School of Medicine, University of the Free State, is thanked for technical and editorial preparation of the manuscript.

Competing interest - The authors declare that they have no financial or personal relationship(s) that may have inappropriately influenced them in writing this article.

\section{ORCID}

JM Kotzé (D) http://orcid.org/0000-0002-0119-3081

H Brits (D) http://orcid.org/0000-0002-5183-5345

\section{References}

1. Rambow B, Adkinson C, Frost $\mathrm{TH}$, et al. Female sexual assault: medical and legal implications. Ann Emerg Med. 1992;21(6):727-31. doi:10.1016/S0196-0644(05)82788-X.

2. McGregor MJ, Du Mont J, Myhr TL. Sexual assault forensic medical examination: is evidence related to successful prosecution? Ann Emerg Med. 2002;39(6):639-47. doi:10.1067/mem.2002.123694.

3. Adams JA, Girardin B, Faugno D. Signs of genital trauma in adolescent rape victims examined acutely. J Pediatr Adolesc Gynecol. 2000;13(2):88. doi:10.1016/S1083-3188(00)00015-2.

4. Lauber AA, Souma ML. Use of toluidine blue for documentation of traumatic intercourse. Obstet Gynecol. 1982;60(5):644-8.

5. McCauley J, Gorman RL, Guzinski G. Toluidine blue in the detection of perineal lacerations in pediatric and adolescent sexual abuse victims. Pediatrics. 1986;78(6):1039-43.

6. McCauley J, Guzinski G, Welch R, et al. Toluidine blue in the corroboration of rape in the adult victim. Am J Emerg Med. 1987;5(2):105-8. doi:10.1016/0735-6757(87)90084-2.

7. Du Plessis K. The anal medical examination of the sexually abused child: findings and their interpretation. Child Abuse Research in South Africa. 2000;1(2):31-5.

8. Zink T, Fargo JD, Baker RB, et al. Comparison of methods for identifying ano-genital injury after consensual intercourse. J Emerg Med. 2010;39(1):113-8. doi:10.1016/j.jemermed.2008.08.024.

9. Slaughter $\mathrm{L}$, Brown $\mathrm{CR}$, Crowley $\mathrm{S}$, et al. Patterns of genital injury in female sexual assault victims. Am J Obstet Gynecol. 1997;176(3):60916. doi:10.1016/S0002-9378(97)70556-8.

10. Seneski PC, Whelan M, Faugno DK, et al. Colour Atlas of Sexual Assault. 1st ed. St. Louis: Mosby; 1997.

11. Signa-Aldrich (now Merck). Toluidine Blue O [Internet]. n.d. [cited 2017 Feb 1]. Available from: http://www.sigmaaldrich.com/catalog/ product/sigma/t0394?lang=en\&region=ZA

12. Sridharan G, Shankar AA. Toluidine blue: A review of its chemistry and clinical utility. J Oral Maxillofac Pathol. 2012;16(2):251-5. doi:10.4103/0973-029X.99081. 
13. Bays J, Lewman LV. Toluidine blue in the detection at autopsy of perineal and anal lacerations in victims of sexual abuse. Arch Pathol Lab Med. 1992;116(6):620-1.

14. Hochmeister MN, Whelan M, Borer UV, et al. Effects of toluidine blue and destaining reagents used in sexual assault examinations on the ability to obtain DNA profiles from postcoital vaginal swabs. J Forensic Sci. 1997;42(2):316-9. doi:10.1520/JFS14119 J.

15. Sommers MS. Defining patterns of genital injury from sexual assault: a review. Trauma Violence Abuse. 2007;8(3):270-80. https://doi. org/10.1177/1524838007303194
16. Signa-Aldrich (now Merck). Toluidine Blue O certified by the Biological Stain Commission [Internet]. n.d. [cited 2017 Feb 1]. Available from: http://www.sigmaaldrich.com/catalog/product/ sial/198161 ?lang=en\&region=ZA\&cm_sp=Insite-_-prodRecCold_ xviews-_-prodRecCold10-1

Received: 10-07-2017 Accepted: 26-09-2017 